\title{
The 2011 off the Pacific coast of Tohoku Earthquake and its aftershocks observed by GEONET
}

\author{
Takuya Nishimura, Hiroshi Munekane, and Hiroshi Yarai \\ Geospatial Information Authority of Japan, Kitasato 1, Tsukuba, Ibaraki 305-0811, Japan
}

(Received April 12, 2011; Revised June 15, 2011; Accepted June 16, 2011; Online published September 27, 2011)

\begin{abstract}
The large displacement induced by the 2011 M 9.0 off the Pacific coast of Tohoku Earthquake was observed by GPS stations of the permanent GPS Earth Observation Network system (GEONET) in northeastern Japan. The displacement was characterized by the eastward displacement and subsidence in the Pacific coastal area. The horizontal displacement exceeded $5.3 \mathrm{~m}$, which is the largest ever detected by GEONET. The mainshock was followed by a sequence of aftershocks. We processed the GPS data through a kinematic positioning strategy to clarify the deformation, including the deformation caused by the mainshock, with high temporal resolutions. The offsets calculated from the kinematic coordinates separately depict the coseismic displacements of the mainshock, the largest aftershock, and the third largest. The fault model for these earthquakes suggests that the largest $(M 7.7)$ and third largest (M 7.3) aftershocks ruptured the southern and northern extensions of the mainshock fault, respectively.
\end{abstract}

Key words: Kinematic GPS, 2011 Tohoku earthquake, mainshock, aftershock, coseismic deformation.

\section{Introduction}

The $M 9.0$ off the Pacific coast of Tohoku Earthquake (hereafter, the 2011 Tohoku earthquake) occurred along the Japan Trench on March 11, 2011. The focal mechanism from the Global CMT Project (Fig. 1) and the aftershock distribution published by the Japan Meteorological Agency (JMA) suggest that the 2011 Tohoku earthquake ruptured the plate interface between the subducting Pacific plate and the overriding Okhotsk plate. The sequence of the 2011 Tohoku earthquakes consisted of a foreshock, the mainshock, and three $M>7$ aftershocks. The $M_{\text {JMA }} 7.3$ foreshock occurred on March 9, 2011, at 2:45 UT (11:45 in Japan Standard Time). The $M_{\mathrm{w}} 9.0$ mainshock occurred on March 11, 2011, at 5:46 UT. The $M_{\mathrm{w}} 7.4,7.7$, and 7.5 aftershocks followed the mainshock at 6:08, 6:15, and 6:25 UT, respectively, on the same day. Roughly 20 min after the mainshock, the Pacific coast of northeastern Japan was inundated by a large tsunami, which caused far more serious damage to human lives and infrastructure than did the strong ground-shaking caused by the earthquake.

Because the Japanese Islands are covered by a dense network of geodetic and seismic networks (i.e. GEONET, Hi-net, K-net, and KIK-net), a vast amount of data was recorded for the 2011 Tohoku earthquake. The GPS Earth Observation Network System (GEONET) is a permanent nationwide GPS array operated by the Geospatial Information Authority of Japan (formerly the Geographical Survey Institute, or GSI). It consists of more than 1300 continuous sites with a real-time transmission of 1-s data sampling

Copyright (C) The Society of Geomagnetism and Earth, Planetary and Space Sciences (SGEPSS); The Seismological Society of Japan; The Volcanological Society of Japan; The Geodetic Society of Japan; The Japanese Society for Planetary Sciences; TERRAPUB.
(Hatanaka et al., 2003; Yamagiwa et al., 2006). GEONET has recorded coseismic and postseismic displacements for many earthquakes that have occurred since 1994, including the earthquake off Tohoku. It has also revealed plate motions and interseismic deformation along the plate boundaries (e.g. Sagiya, 2004). Before the 2011 Tohoku earthquake, a contraction in the east-west direction was observed in northeastern Japan (Sagiya et al., 2000) and the plate interface was estimated to be coupled along the Japan Trench (e.g. Nishimura et al., 2004).

On a routine basis, the GEONET GPS data are processed with Bernese 5.0 software to estimate the daily coordinates of the stations (Nakagawa et al., 2009). Moreover, the static coordinates are estimated at 3-h intervals using 6-h data to rapidly detect signals related to episodic events. However, the site coordinates estimated from the static positioning by the GEONET routine do not have enough temporal resolution to capture any rapid evolution of the deformation (e.g. Larson and Miyazaki, 2008). In the sequence of the 2011 Tohoku earthquakes, several $M>7$ aftershocks occurred within $1 \mathrm{~h}$ after the mainshock. These aftershocks have the potential to cause displacements of more than several centimeters at the GEONET stations.

In this paper, we focus on the coseismic and postseismic deformation revealed by GEONET. We also show the results of kinematic positioning of GPS data to distinguish between the displacements caused by the mainshock and those caused by the aftershocks. Finally, we present simple models that assume rectangular faults for the mainshock and aftershocks. A detailed analysis of the distribution of coseismic and postseismic slip as estimated from the GEONET data is summarized in another paper (Ozawa et al., 2011). 

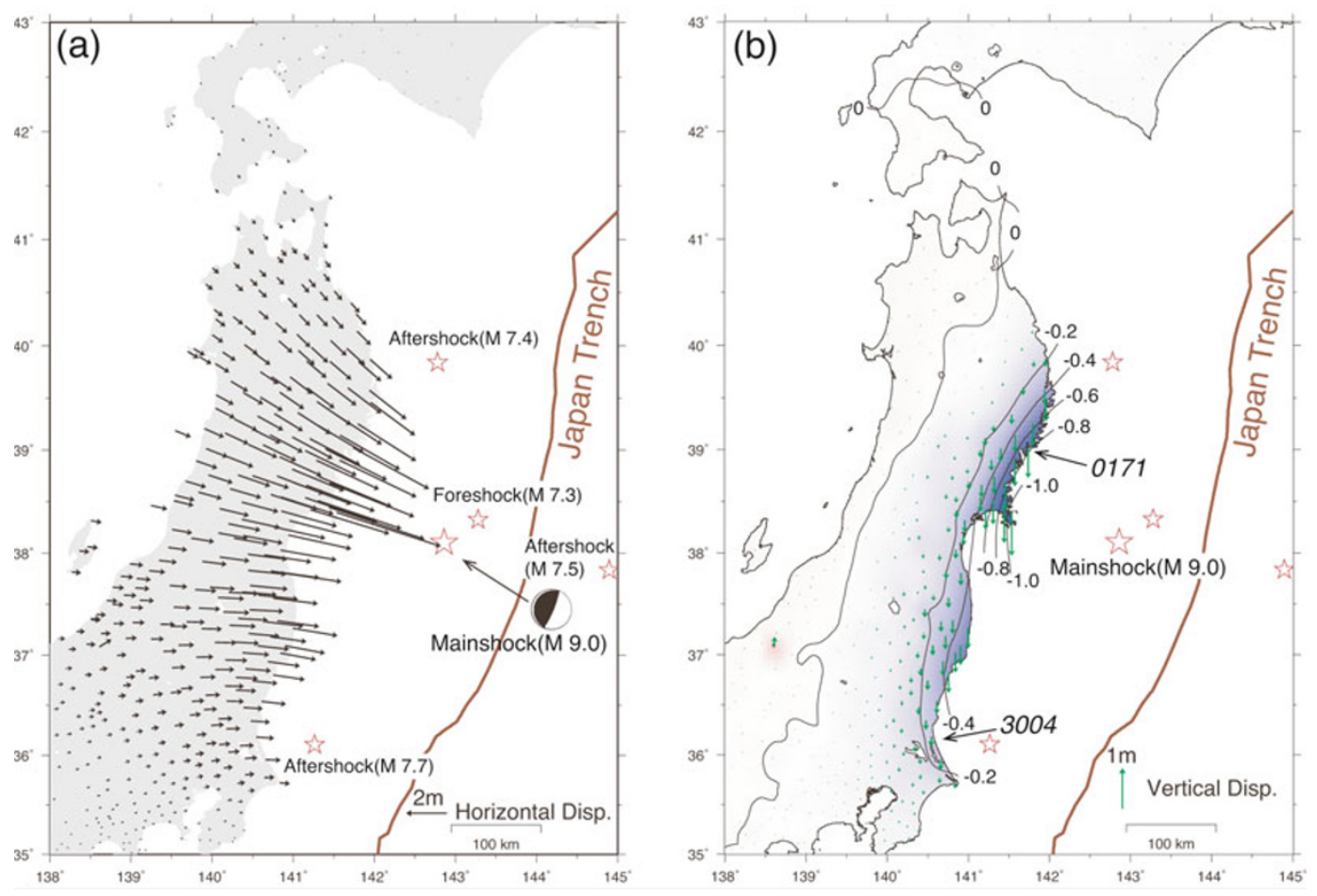

Fig. 1. Coseismic displacement of the 2011 Tohoku earthquake based on daily coordinates of the routine GEONET analysis. (a) Horizontal displacement. The focal mechanism of the mainshock is from the Global CMT Project (http://www.globalcmt.org/). (b) Vertical displacement. The four-digit number represents the GPS site ID shown in Fig. 2.

\section{The 2011 Tohoku Earthquake As Revealed by GEONET}

The earthquake caused the suspension of electric power and data transmission at most GEONET stations along the Pacific coast of northeastern Japan. Hundreds of stations were temporarily unable to record data because of lengthy power failures that lasted for several days or even weeks. The number of suspended GEONET stations decreased to 18 by April 6, 2011. In this study, we have used 30-s sampled GPS data which were automatically downloaded, as well as those directly collected from the GPS receiver memory on site by GSI staff.

Figure 1 shows the coseismic displacement caused by the 2011 Tohoku earthquake. This was estimated based on the routine GEONET analysis by differencing the daily coordinates for March 10 through 12. The observed coseismic displacement includes not only the displacement by the mainshock, but also that by the aftershocks and transient postseismic signals. The horizontal displacement reached $5.3 \mathrm{~m}$ in the Oshika Peninsula near the epicenter, which is the largest displacement ever observed by GEONET. The area where the horizontal displacement exceeded $1 \mathrm{~m}$ stretched for approximately $420 \mathrm{~km}$ along the Pacific coast and reached the Japan Sea coast. The vertical deformation was characterized by subsidence as great as $1.2 \mathrm{~m}$ along the Pacific coast. However, the coastal area facing the Japan Sea was uplifted by a few centimeters, which is consistent with the predicted deformation by reverse faulting in an elastic half-space (Okada et al., 1985). A postseismic deformation following the mainshock was also observed. The maximum postseismic horizontal displacement reached $41 \mathrm{~cm}$ on the 25 th day after the mainshock. Several sites in the Pacific coastal area were uplifted significantly in the postseismic period, which contrasts with the coseismic subsidence.

\section{Kinematic Analysis of GPS Data}

A displacement based on static daily coordinates has the advantage of precision but is affected by the many events that occur in a day. We analyzed GPS data by kinematic positioning to overcome this disadvantage. GPS data with 30 -s sampling were processed to estimate 300 -s coordinates using GIPSY 6.0, which uses the precise-point-positioning (PPP) strategy (Zumberge et al., 1997). Precise orbits and clocks determined by the Jet Propulsion Laboratory (JPL) were used for processing the GPS data. The GIPSY software provides two models (i.e., white noise and random walk) to estimate site coordinates. We chose the whitenoise model, which is appropriate to detect a coseismic offset (Larson and Miyazaki, 2008). In addition, to follow highly-rapid deformation, we estimated 30-s coordinates using the final orbits and high-rate clocks of the International GNSS Service (IGS).

Figure 2 shows the estimated 300-s coordinates as well as daily coordinates from the routine analysis. The daily coordinates approximately coincide with the daily averages of the 300-s coordinates. Therefore, the difference between March 10 and 12 in the 300-s coordinates is almost equal to that in the daily coordinates. However, displacements produced by the mainshock, the largest aftershock, and transient changes afterward, are clearly recognized in the 300-s coordinates (Figs. 2(a-c)). We fitted an exponential-decay function for the observed transient in a form of $u(t)=A\left(1-\exp \left(1-t / t_{0}\right)\right)$, where $u, t, t_{0}$, and $A$ 
(a)
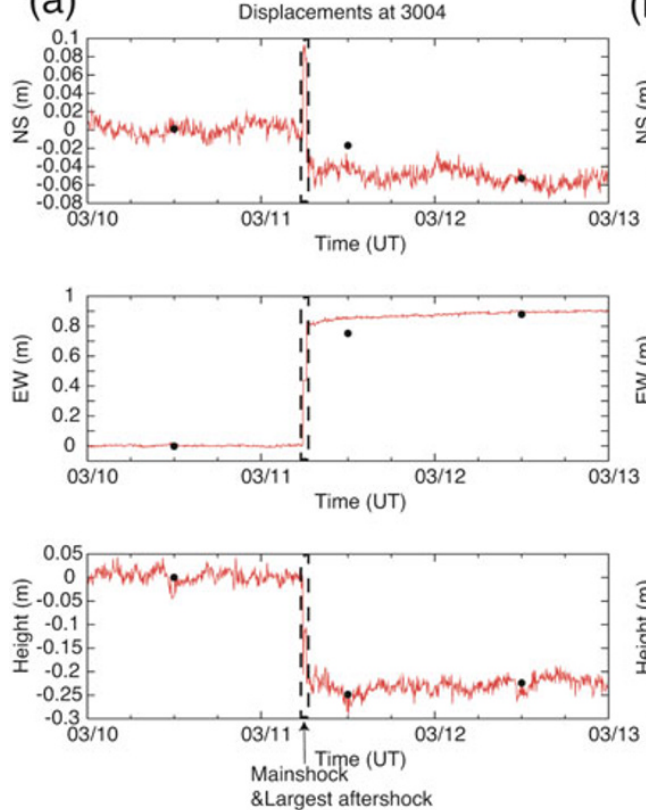

(b)

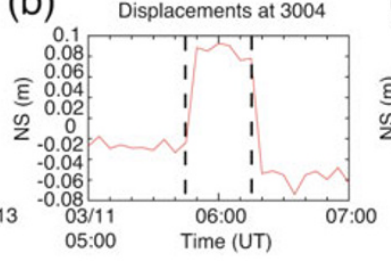

(c)

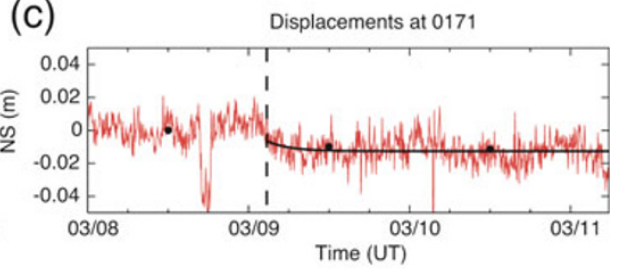

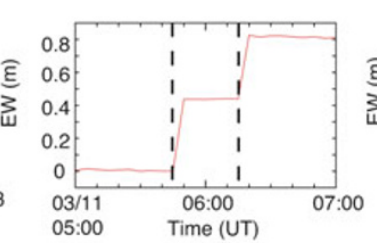
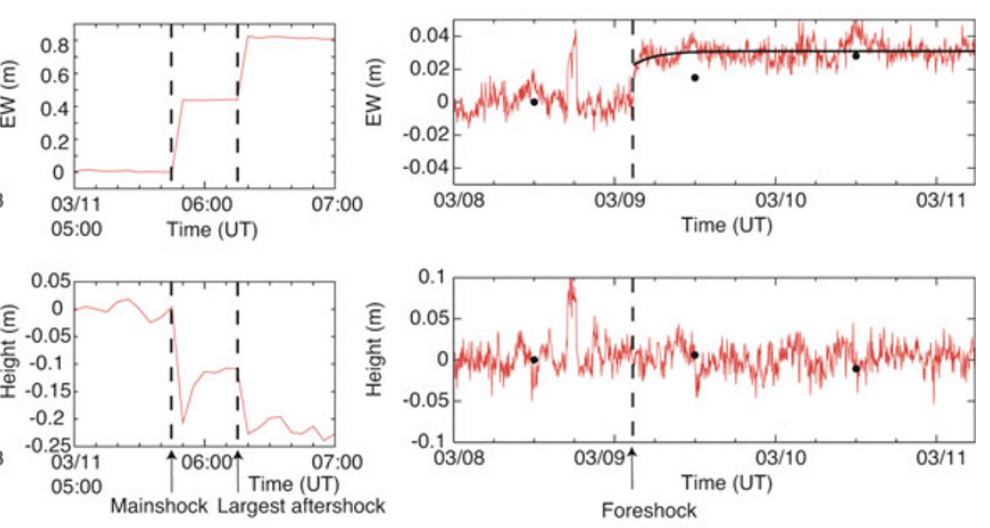

Fig. 2. Time series from selected GPS sites. The locations of the sites are shown in Fig. 1(b). (a) Time series for three days, including the mainshock, at the 3004 site. (b) Enlargement of the time series at the 3004 site. Clear offsets were recognized for both the mainshock and the largest aftershock. (c) Time series from before the mainshock at the 0171 site. An offset for the foreshock and subsequent transient deformation were recognized. The solid curves are exponential-decay curves fitting horizontal components of the transient deformation.

is displacement, time, decay-time constant, and amplitude of transient displacement, respectively. It suggests $\sim 0.1$ days of a decay time for the postseismic deformation of the foreshock. We also investigated whether any anomalous deformation occurred just before the mainshock. Figure 2(c) shows time series of 300-s coordinates at the station near the mainshock epicenter. Although an offset for the foreshock and a subsequent transient change are recognizable, no anomalous changes above the noise level can be detected.

\section{Coseismic Displacements and Their Fault Model}

GPS time series based on kinematic GPS positioning successfully discriminate among offsets for earthquakes and transient changes. We calculated the coseismic displacement of each earthquake separately. Site coordinates for 30 -s epochs instead of 300-s epochs were used to extract the static offset of each earthquake, so as to minimize postseismic signals following the earthquakes. Coseismic displacement is defined as the difference in the median of a coordinate for 11 epochs (i.e., $300 \mathrm{~s}$ ) before and after the earthquake. The specified periods for each earthquake were 2:40-2:45 (pre) and 2:50-2:55 (post) for the foreshock on March 9, 5:41-5:46 (pre) and 5:55-6:00 (post) for the mainshock on March 11, 6:10-6:15 (pre) and 6:20-6:25 (post) for the largest aftershock, 6:21-6:26 (pre) and 6:31$6: 36$ (post) for the second-largest aftershock, and 6:016:06 (pre) and 6:11-6:16 (post) for the third-largest aftershock. As shown in Fig. 3, we can recognize significant displacements for each of the earthquakes, with the exception of the second-largest aftershock, which occurred far away from the onshore GPS sites. The eastward displacements for the identified earthquakes are consistent with the focal mechanisms, which are of the low-angle thrust type according to the Global CMT Project. The largest aftershock produced the maximum horizontal displacement of $44 \mathrm{~cm}$ (Fig. 3(c)). The vertical displacement is rather noisy but reveals as much as $16 \mathrm{~cm}$ of subsidence on the Pacific coast for the largest aftershock. Because the displacement caused by the largest aftershock near its epicenter was comparable with that by the mainshock there, the slip estimation of the 2011 Tohoku earthquake, based on daily coordinates, must contain a bias for the southern limit of the slip area.

We constructed simple fault models that assumed rectangular faults in an elastic half-space (Okada, 1985) to explain the displacement shown in Fig. 3. The nonlinear inversion method with prior information (Matsu'ura and Hasegawa, 1987) was used to estimate the parameters of a rectangular fault. In addition to solving for the fault parameters (e.g., location, depth, length, width, strike, dip, rake, and slip), we estimated the translation of each GPS site to account for large-scale noises contained in the estimated coordinates. The estimated parameters are listed in Table 1. To avoid a non-unique unstable result in the nonlinear inversion, the inversion method used incorporates probable parameters deduced from other geophysical information, including the geometry of the plate interface (Nakajima and Hasegawa, 2006) and the focal mechanisms from the Global CMT Project as a priori information. It means that some parameters were tightly constrained to initial values. Data resolution ranging between 0 and 1 , in Table 1 , is a diagonal term of partial resolution matrices corresponding to the observed data (Matsu'ura and Hasegawa, 1987). A value 

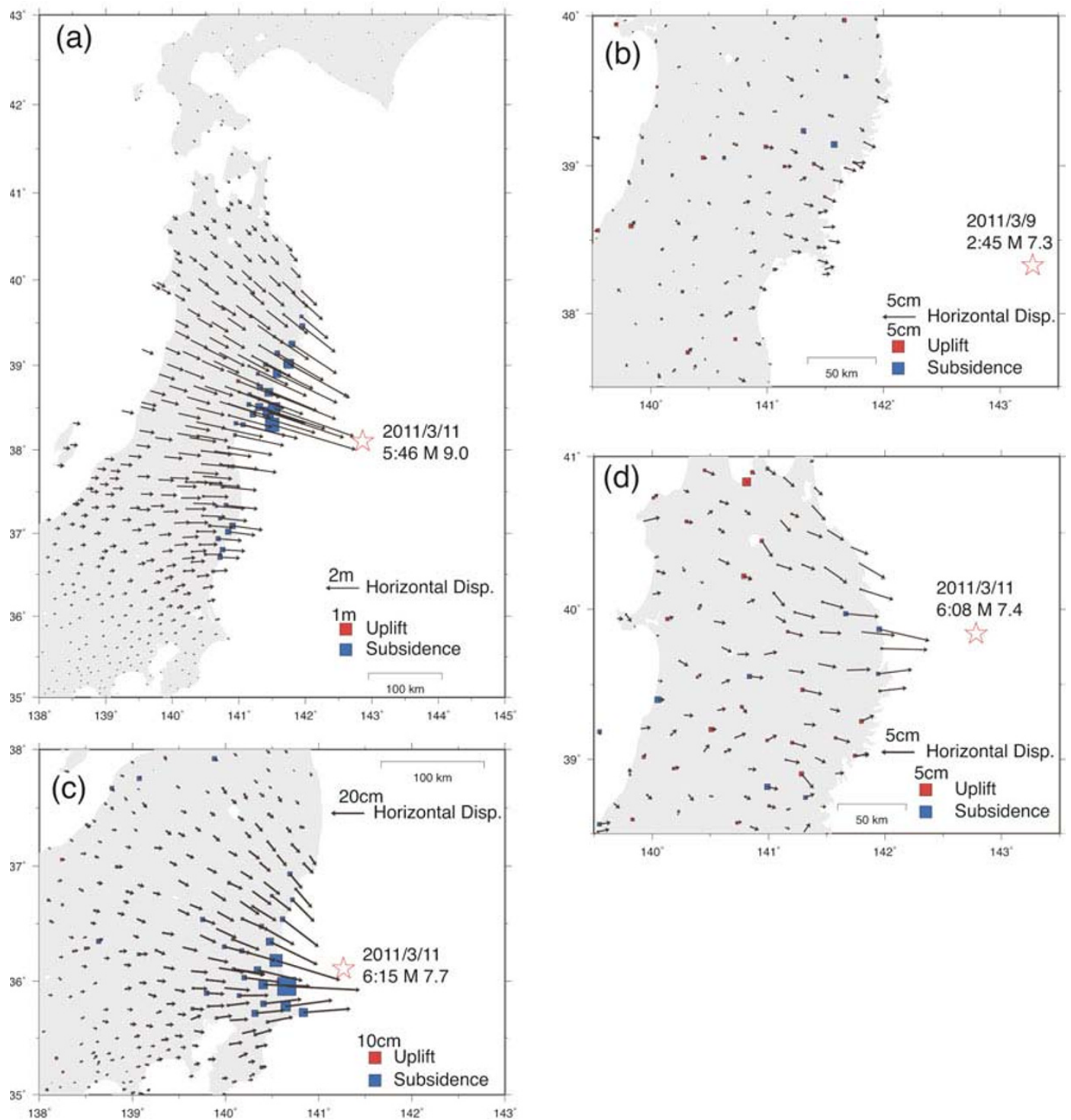

Fig. 3. Coseismic displacement based on 30-s coordinates estimated from kinematic GPS analysis for (a) the $M_{\mathrm{W}} 9.0$ mainshock, (b) the $M_{\mathrm{JMA}} 7.3$ foreshock, (c) the $M_{\mathrm{w}} 7.7$ largest aftershock, and (d) the $M_{\mathrm{w}} 7.4$ third-largest aftershock.

of 1 means the estimated parameter completely depends on the observed data, whereas zero means it is fixed to initial values. While modeling the mainshock, we assumed three rectangular segments along the Japan Trench to express the huge $M 9.0$ earthquake. According to Akaike's Information Criteria (AIC; Akaike, 1973), the optimal number of segments is three or more for the mainshock displacement. We chose three segments for practical reasons because a larger number of parameters resulted in a greater dependence of the estimated parameters on a priori values with the inversion method used. The estimated horizontal locations are generally constrained by the observed data (Table 1) except for the foreshock which has a small signal-to-noise ratio of the observed displacement (Fig. 3(b)). The locations of the landward edges of the fault are constrained by the observed data in the most cases. However, offshore edges are not constrained without a priori information of some parameters, particularly dip, because the land GPS data have little resolving power of offshore slip $150 \mathrm{~km}$ away from the coastline in northeastern Japan (Nishimura et al., 2004).
For the mainshock, three rectangular faults suggest that the fault rupture extended for approximately $350 \mathrm{~km}$ along the Japan Trench. The slip is greater in northern segments, although many aftershocks occurred in the southern part of the source area. The total moment magnitude of the mainshock is estimated at 8.87 with a rigidity of $40 \mathrm{GPa}$, which is smaller than that of the Global CMT Project. This discrepancy may be due to the absence of offshore slip near the trench axis, which may be attributed to poor resolving power of the land geodetic data because a large offshore displacement observed by a GPS-acoustic technique requires a large slip near the trench (Sato et al., 2011). Despite the simplicity of the assumed models, the observed displacement can be reasonably explained (see Fig. 4). The locations of all fault models are plotted in Fig. 4. Note that the faults of the large aftershocks did not overlap the mainshock faults. We deduce that those aftershocks ruptured the northern and southern extensions of the mainshock faults. The largest aftershock is placed just south of the southernmost segment of the mainshock. This suggests that the largest af- 

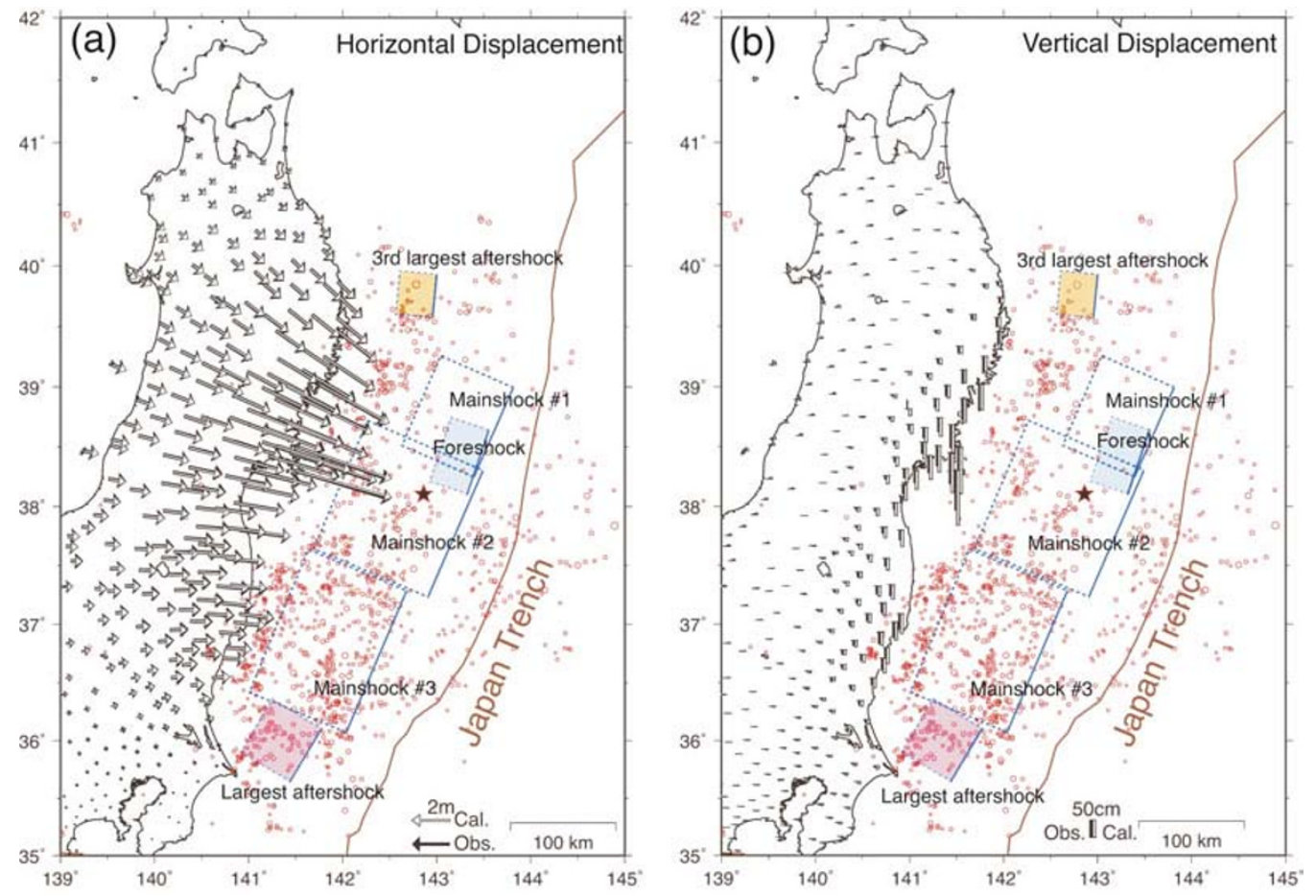

Fig. 4. Coseismic displacement and fault models for the sequence of the 2011 Tohoku earthquakes. The solid and open symbols represent the observed and calculated displacements for the mainshock, respectively. The dotted rectangles show the fault locations of the mainshock, foreshock, largest aftershock, and third-largest aftershock. The solid line in each rectangle shows the upper edge of the fault. A star represents the epicenter of the mainshock. Circles represent those of $M>4$ aftershocks occurring until March 20, 2011. (a) Horizontal displacement. (b) Vertical displacement.

Table 1. Estimated fault parameters for earthquakes.

\begin{tabular}{|c|c|c|c|c|c|c|c|c|c|c|}
\hline Earthquake & $\begin{array}{l}\text { Latitude* } \\
\left({ }^{\circ}\right)\end{array}$ & $\begin{array}{c}\text { Longitude* } \\
\left({ }^{\circ}\right)\end{array}$ & $\begin{array}{l}\text { Depth* } \\
(\mathrm{km})\end{array}$ & $\begin{array}{l}\text { Length } \\
(\mathrm{km})\end{array}$ & $\begin{array}{l}\text { Width } \\
(\mathrm{km})\end{array}$ & $\begin{array}{l}\text { Strike } \\
\left({ }^{\circ}\right)\end{array}$ & $\begin{array}{l}\text { Dip } \\
\left({ }^{\circ}\right)\end{array}$ & $\begin{array}{c}\text { Rake } \\
\left({ }^{\circ}\right)\end{array}$ & $\begin{array}{l}\text { Slip } \\
(\mathrm{m})\end{array}$ & $M_{\mathrm{w}}^{* *}$ \\
\hline Foreshock & $\begin{array}{c}38.641 \pm 0.116 \\
(0.01)\end{array}$ & $\begin{array}{c}143.555 \pm 0.089 \\
(0.01)\end{array}$ & $\begin{array}{c}8.3 \pm 9.7 \\
(0.05)\end{array}$ & $\begin{array}{l}63 \pm 39 \\
(0.96)\end{array}$ & $\begin{array}{l}39 \pm 72 \\
(0.86)\end{array}$ & $\begin{array}{l}199 \pm 9 \\
(0.23)\end{array}$ & $\begin{array}{l}17 \pm 10 \\
(0.02)\end{array}$ & $\begin{array}{c}93 \pm 10 \\
(0.08)\end{array}$ & $\begin{array}{c}1.34 \pm 3.77 \\
(1.00)\end{array}$ & 7.34 \\
\hline $\begin{array}{c}\text { Mainshock } \\
\# 1\end{array}$ & $\begin{array}{c}38.994 \pm 0.020 \\
(0.68)\end{array}$ & $\begin{array}{c}143.815 \pm 0.015 \\
(0.69)\end{array}$ & $\begin{array}{c}8.0 \pm 0.1 \\
(0.01)\end{array}$ & $\begin{array}{l}90 \pm 3 \\
(0.89)\end{array}$ & $\begin{array}{l}76 \pm 2 \\
(0.95)\end{array}$ & $\begin{array}{c}204 \\
(0.00)\end{array}$ & $\begin{array}{c}16 \pm 0.2 \\
(0.08)\end{array}$ & $\begin{array}{c}119 \pm 0.6 \\
(1.00)\end{array}$ & $\begin{array}{c}40.88 \pm 2.00 \\
\quad(1.00)\end{array}$ & $8.63^{* * *}$ \\
\hline $\begin{array}{c}\text { Mainshock } \\
\quad \# 2\end{array}$ & $\begin{array}{c}38.303 \pm 0.020 \\
(0.76)\end{array}$ & $\begin{array}{c}143.494 \pm 0.013 \\
(0.69)\end{array}$ & $\begin{array}{l}7.9 \pm 0.1 \\
(0.01)\end{array}$ & $\begin{array}{l}130 \pm 2 \\
(0.97)\end{array}$ & $\begin{array}{l}122 \pm 1 \\
(0.98)\end{array}$ & $\begin{array}{c}204 \\
(0.00)\end{array}$ & $\begin{array}{c}17 \pm 0.2 \\
(0.34)\end{array}$ & $\begin{array}{c}90 \pm 0.6 \\
(1.00)\end{array}$ & $\begin{array}{c}17.36 \pm 0.37 \\
(1.00)\end{array}$ & $8.63^{* * *}$ \\
\hline $\begin{array}{c}\text { Mainshock } \\
\quad \# 3\end{array}$ & $\begin{array}{c}37.285 \pm 0.031 \\
(0.57)\end{array}$ & $\begin{array}{c}142.680 \pm 0.018 \\
(0.21)\end{array}$ & $\begin{array}{l}7.9 \pm 0.1 \\
(0.01)\end{array}$ & $\begin{array}{l}147 \pm 3 \\
(0.92)\end{array}$ & $\begin{array}{l}104 \pm 2 \\
(0.97)\end{array}$ & $\begin{array}{c}204 \\
(0.00)\end{array}$ & $\begin{array}{c}16 \pm 0.2 \\
(0.19)\end{array}$ & $\begin{array}{c}85 \pm 0.6 \\
(1.00)\end{array}$ & $\begin{array}{l}4.72 \pm 0.10 \\
\quad(1.00)\end{array}$ & $8.24^{* * *}$ \\
\hline Third largest aftershock & $\begin{array}{c}39.927 \pm 0.075 \\
(0.32)\end{array}$ & $\begin{array}{c}143.002 \pm 0.074 \\
(0.59)\end{array}$ & $\begin{array}{c}30.9 \pm 7.2 \\
(0.49)\end{array}$ & $\begin{array}{l}40 \pm 9 \\
(0.19)\end{array}$ & $\begin{array}{l}35 \pm 9 \\
(0.13)\end{array}$ & $\begin{array}{r}186 \pm 7 \\
(0.51)\end{array}$ & $\begin{array}{l}12 \pm 7 \\
(0.56)\end{array}$ & $\begin{array}{l}73 \pm 9 \\
(0.26)\end{array}$ & $\begin{array}{c}1.67 \pm 0.73 \\
(1.00)\end{array}$ & 7.24 \\
\hline Largest aftershock & $\begin{array}{c}36.106 \pm 0.049 \\
(0.91)\end{array}$ & $\begin{array}{c}141.777 \pm 0.026 \\
(0.82)\end{array}$ & $\begin{array}{c}8.7 \pm 0.9 \\
(0.16)\end{array}$ & $\begin{array}{l}59 \pm 6 \\
(1.00)\end{array}$ & $\begin{array}{l}61 \pm 5 \\
(1.00)\end{array}$ & $\begin{array}{c}211 \pm 3 \\
(1.00)\end{array}$ & $\begin{array}{l}26 \pm 2 \\
(0.96)\end{array}$ & $\begin{array}{l}104 \pm 4 \\
(0.77)\end{array}$ & $\begin{array}{c}3.76 \pm 0.51 \\
(1.00)\end{array}$ & 7.76 \\
\hline
\end{tabular}

Optimum values of fault parameters are listed with $1 \sigma$ uncertainties and data resolution in the parentheses.

${ }^{*}$ Locations point to a northern corner of an upper edge of a rectangular fault.

${ }^{*}$ Rigidity is assumed to be $40 \mathrm{GPa}$.

*** Total moment magnitude is 8.87 .

tershock was triggered by large stress increases at the edge of the mainshock rupture. The foreshock fault was included in the mainshock faults and located just north of the mainshock epicenter. A significant postseismic deformation was observed for the foreshock (Fig. 2(c)), which may have affected the occurrence of the mainshock. Hence, in future, a detailed analysis of the transient slip evolution following the foreshock is needed to clarify the relation between the foreshock and the mainshock.

\section{Conclusion}

The 2011 M 9.0 Tohoku earthquake produced a great deformation of the Japanese Islands in terms of both extent and magnitude. GEONET presents a detailed pattern of the coseismic displacements of the foreshock, mainshock, and aftershocks. These displacements, which were integrated with daily coordinates from a traditional GPS analysis, were discriminated by kinematic positioning of the GPS data. The simple fault models for these earthquakes suggest that the largest aftershocks ruptured a region left unruptured by the mainshock, whereas the source region of the foreshock was included by that of the mainshock. 
The destructive Tohoku earthquake led to tragic consequences for the Japanese people. Nevertheless, this event has left us with abundant geophysical data for a great ( $M 9$ class) earthquake, such as has never been recorded anywhere before. These data must be used to mitigate the impact of future disasters.

Acknowledgments. The authors would like to acknowledge Prof. Shin'ichi Miyazaki and an anonymous referee for their comment. The authors thank the Japan Meteorological Agency for providing the earthquake catalogue. The authors are indebted to GSI colleagues for maintaining and restoring GEONET.

\section{References}

Akaike, H., Information Theory and an Extension of the Maximum Likelihood Principle, in 2nd international symposium on Information Theory, edited by B. N. Petrov and F. Csaki, 267-281, Akademiai Kiado, Budapest, 1973.

Hatanaka, Y., T. Iizuka, M. Sawada, A. Yamagiwa, Y. Kikuta, J. M. Johnson, and C. Rocken, Improvement of the Analysis Strategy of GEONET, Bull. Geogr. Surv. Inst., 49, 11-37, 2003.

Larson, K. M. and S. Miyazaki, Resolving static offsets from high-rate GPS data: the 2003 Tokachi-oki earthquake, Earth Planets Space, 60, 801-808, 2008.

Matsu'ura, M. and Y. Hasegawa, A maximum likelihood approach to nonlinear inversion under constraints, Phys. Earth Planet. Inter., 47, 179$187,1987$.

Nakagawa, H., T. Toyofuku, K. Kotani, B. Miyahara, C. Iwashita, S. Kawamoto, Y. Hatanaka, H. Munekane, M. Ishimoto, T. Yutsudo, N. Ishikura, and Y. Sugawara, Development and validation of GEONET new analysis strategy (Version 4), J. Geogr. Surv. Inst., 118, 1-8, 2009 (in Japanese).
Nakajima, J. and A. Hasegawa, Anomalous low-velocity zone and linear alignment of seismicity along it in the suducted Pacific slab beneath Kanto, Japan: Reactivation of subducted fracture zone?, Geophys. Res. Lett., 33, L16309, 2006.

Nishimura, T., T. Hirasawa, S. Miyazaki, T. Sagiya, T. Tada, S. Miura, and K. Tanaka, Temporal change of interplate coupling in northeastern Japan during 1995-2002 estimated from continuous GPS observations, Geophys. J. Int., 157, 901-916, 2004.

Okada, Y., Surface deformation due to shear and tensile faults in a halfspace, Bull. Seismol. Soc. Am., 75, 1135-1154, 1985.

Ozawa, S., T. Nishimura, H. Suito, T. Kobayashi, M. Tobita, and T. Imakiire, Coseismic and postseismic slip of the 2011 magnitude- 9 TohokuOki earthquake, Nature, 475, 373-376, doi:10.1038/nature10227, 2011.

Sagiya, T., S. Miyazaki, and T. Tada, Continuous GPS array and presentday crustal deformation of Japan, Pure Appl. Geophys., 157, 23032322, 2000.

Sagiya, T., A decade of GEONET: 1994-2003-The continuous GPS observation in Japan and its impact on earthquake studies, Earth Planets Space, 56, xxix-xli, 2004.

Sato, M., T. Ishikawa, N. Ujihara, S. Yoshida, M. Fujita, M. Mochizuki, and A. Asada, Displacement above the hypocenter of the 2011 TohokuOki Earthquake, Science, 332, 1395, doi:10.1126/science.1207401, 2011.

Yamagiwa, A., Y. Hatanaka, T. Yutsudo, and B. Miyahara, Real-time capability of GEONET system and its application to crust monitoring, Bull. Geogr. Surv. Inst., 53, 27-33, 2006.

Zumberge, J. F., M. B. Heflin, D. C. Jefferson, M. M. Watkins, and F. H. Webb, Precise point positioning for the efficient and robust analysis of GPS data from large network, J. Geophys. Res., 102, 5005-5017, 1997.

T. Nishimura (e-mail: t_nisimura@gsi.go.jp), H. Munekane, and H. Yarai 